marked likeness between the annual variation of the temperature range and the annual variation of the declination range at the Kew Observatory.

There yet remains a question which is nearly allied to the present inquiry. If the sun affects the earth in a variety of ways, and if the planets affect the sun, why should not the moon affect the earth? Now it is known to affect terrestrial magnetism, producing a well-marked variation of a tidal nature, that is to say with two maxima and minima in each lunar day, and there are also indications of a variation with only one maximum and minimum.

Again, Mr. Park Harrison was the first to point out that terrestrial temperature is influenced by the relative position of the sun and moon.

The writer of this article has found in the daily temperature range at the Kew Observatory an unmistakable reference to the phase of the moon.

In summer when the fuil moon is low in the heavens, we have a less decided reference, which seems to imply a maximum of daily temperature range about new moon and also about full moon. But in winter, when the full moon is high, we have a very decided reference showing a maximum of daily temperature range about new moon, and a minimum about full moon.

Again, in the magnetic ranges at Kew the same features occur, namely, in summer a maximum range at new and at full moon, and in winter a maximum at new and a minimum at full moon.

The vinter lunar variations of the temperature and declination ranges at Kew are exhibited in the Diagrams $L$ and $M$, from which it will be seen that there is a very decided likeness between the two.

These last diagrams are especially interesting because they exhibit an influence which appears to be similar in form to that which the planets may be supposed to prom duce upon the surface of the sun. This, however, is a question which can only be decided by further investigation.

If we now bring together the results of these three papers we may compare the three problems, solar research, terrestrial magnetism, and meteorology, to three corners of a triangle that are bound together. Of their three relations we are, it may be said, perfectly certain of the connection between solar research and terrestrial magnetism. The connection between solar research and meteorology

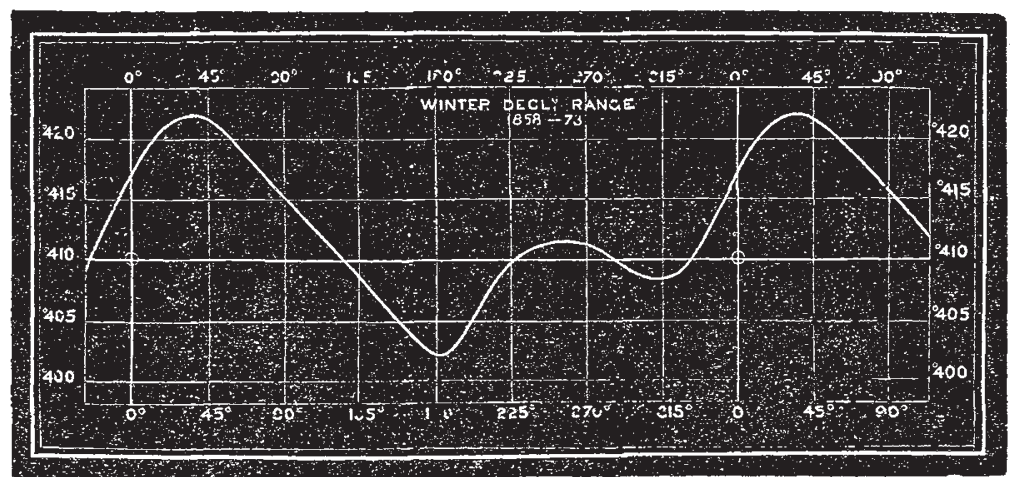

Diagram $M$.

is perhaps not so well defined, but our evidence is here supplemented by independent traces of a connection between magnetism and meteorology. Thus the three things hang together, and scientific prudence points to the desirability of their being studied together as a whole, a consideration which will not, I trust, be overlooked in the contemplated reorganisation of British metecrology.

I would desire now to conclude by asking, in all honesty, Have we not here a plea for the establishment of some institution that will keep a daily watch upon that luminary which is thus seen to affect us in such a variety of ways?

BALFOUR STEWART

\section{THE SOUTH AFRICAN MUSEUM}

UR notice of the condition of the South African Museum, and the various sums allotted to research by the Government of the Colony, has called forth some criticisms on the part of the Cape-town Standard and Mail of April 7. "What NATURE and other scientific organs in Europe mean by "research," it states, "is not what the responsible advisers of the Cape mean by their favouring grãnts. It would not be saying too much, nor putting it too strongly, to assert that there is no scientific research carried on in connection with any botanical gardens in South Africa. In regard to our museums there is some genuine work being done; at all events in the South African and Albany museums original observations are being recorded. As to our libraries which absorb 2,000l. per annum of the public money, the less said, perhaps, the better. The South African Library, as far as standard works in such branches of science as anatomy, chemistry, mineralogy, natural philosophy, \&c., are concerned, is simply deficient, and unaccountably so, considering the demands of these departments and the standing of some of the directors. The only sums voted' for purely original scientific work are those for 'Geological Researches,' for the publication of Dr. Bleek's Bushman Researches, and for the Meteorological Commission. With the exception of the first of these, which amounts to $1,500 l$., research in the sense NATURE must mean, is fostered by only some four or five hundred pounds." Tne writer then goes on to describe the consequences of Dr. Bleek's death; the linguistic and ethnological researches he was carrying on have been stopped, and instead of appointing a qualified scholar to fill his place, the Government allowed his office and salary "to be absorbed into the general and ignoble management of the South African Library, which is only a representative of Mudie, being conducted in the charitable idea of providing, at three pounds sterling per annum, the current literature of the day to subscribers who for the same reading would have to pay in a circulating library about four times the amount.... 'Novels are the solace of my life,' was the plea (of Mir. Goodliffe) from the chair in favour of continuing a national institution subsidised by the Government of the Colony, and therefore supported from the revenue of the country, as a receptacle for the custodianship of the popular writings of the period. The scientific work of South Africa has been done by amateurs holding no professed natural history appointments." The Gill College Herbarium now receives a subsidy of rool. a year, but "Prof. Macowan worked at the botany of the Colony for thirteen years before he received any grant to enable him to prosecute the study, or to cover the expenses of preserving a large herbarium." The Colonial Herbarium in Capetown " has a collection of types of the very highest value to Cape botany-those arranged and classified by Dr. Harvey. It has the collections of Dr. Pappe, the late Colonial botanist, consisting of thousands of species, which were bought by a former Government for some $200 l$. Other collections more or less valuable are also in the Herbarium." But 
" the greater part of these interesting and valuable plants has been destroyed by rain leaking through the roof of the library buildings into the room where they are kept, and by the ravages of moths, \&c. In a short time the herbarium will be simply nothing but a mass of uninteresting fragments. We understand that some time back the Parliament voted a small sum to be expended in putting the herbarium into order. How far anything could possibly have been done by those in charge may be learned from the fact that Dr. Rehman, the Austrian botanist, found whole fasiculi destroyed."

\section{SFONGY IRON FILTERS}

IN a paper presented by Prof. Frankland, F.R.S., and read before the Royal Scciety, Mr. Gustav Bischof describes numerous experiments made with spongy iron filters and with charcoal filters. He states that chemical analysis is incapable of discriminating between living or dead, fresh or putrescent organic matters. The microscope reveals their nature more fully ; but it is nevertheless frequntly a matter of great difficulty to decide as to the existence or non-existence of Bacteria of putrefaction, or their germs, in water.

We must refer our readers to the paper for a full account of the experiments and the conditions under which they were performed. Mr. Bischof states that they show that Bacteria present in drinking water are not killed in passing through charcoal and are killed in passing through spongy iron.

He adds: "I believe that the action of spongy iron on urganic matters largely consists in a reduction of ferric hydrate by organic impurities in water. We know that even such organic matters as straw or branches are capable of reducing ferric to ferrous hydrate. We know that even sach indestructible organic matter as linen and cotton fibres are gradually destroyed by rust stains. This action is slow when experimenting upon ordinary ferric hydrate, but it niay, in stain nuscendi, be very energetic, the more so if we consider the nature of the organic matter in water. Ferric hydrate is always formed in the upper part of a layer of spongy iron, when water is passed through that $\mathrm{m}$ aterial. The ferrous hydrate resulting from the reduction by organic matter may be re-oxidised by oxygen dissolved in the water, and thus the two reactions repeat themselves. This would explain why the action of spongy iron continues so long.

"It is, however, quite certain that there is also a reducing action taking plice when ordinary water is passed through spongy iron. This is clearly indicated by the reduction of nitrates.

"Our knowledge of those low organisms, which are believed to be the cause of certain epidemics, is as yet too limited to allow of direct experiments upon them. It is not improbable that, like the Bacteria of putrefaction, they are rendered harmless when water containing them passes through spongy iron; but until we possess the means of isolating these organisms, this question can only be definitively settled by practical experience."

\section{CENTROIDS AND THEIR APPLICATION TO SOME MECHANICAL PROBLEMS ${ }^{\mathrm{I}}$}

THE principal object of the following paper is to suggest the use of a more general form than is commonly employed in the statement of some of the more important theorems of elementary mechanics. Such a generalisation, if in itself satisfactory, has two-fold advantages; it both facilitates the direct solution of problems otherwise apparently complex, and it enables a common method to be employed in an infinite variety of cases, each of which otherwise has to be treated in its own special way. The methods to be described are purely geometric, and admit in all cases of graphic solutions. In the study of mechanism and in all applications of mechanics to engineering work this is a matter of considerable importance, for graphic methods have such enormous advantages in these cases that they must supplant all others when they give equally good results.

By the centruid of any body $A$ relatively to another $B$ is meant the locus of the instantaneous centres of $A$ in its motion relatively to $B .^{2}$ The expression includes two things, which must be dis-

${ }^{r}$ Abstract of a paper read before Section A of the British Association at Glasgow, by Pruf. Alex. B. W. Keanedy, C E., of University Colege, London.

2 The word centroid was suggested to the author by his colleague, Prof. W. K. Clifford. tinguished from each other; - (i.) the locus as part of the movin body $A$, (ii.) the locus as part of the body $B$ relatively to which $A$ 's motion is observed, and which may for convenience be regarded as fixed. These loci may be entirely öifferent as to form, but in all their properties they are absolutely similar and reciprocal. It would therefore be wrong to give them different names, they can be distinguiched, when nects sary, as the centroid of a body, and the centroid for the motion of a body respectively. The centroid of $A$ is therefore the locus upon $A$ of its inst. centres relatively to $B$; the centroid for the motion of $A$ is the locus upon $B$ of the same centres.

The following are the most important characteristics of these curves. As the bodies to which they belong move the centroids roll upon each other, and every point in each becomes in turn the inst. centre. Their rolling, therefore, represents continuously the whole motion of the bodies (considered as changes of position merely), quite irrespective of their form ; in other words it defines the path of motion of all points in the bodies. The two centroids have always one point in common-their point of contact-this point being the instantaneous centre. This point may be included in both bodies, and has no motion relatively to either. Any motion which it has must therefore be common to both, so that it may be entirely neglected in investigating their relative motions. In problems affecting the motion of either body relatively to a third this is often of much use.

For the sake of definiteness it has been presupposed in the foregoing paragraphs that the motions referred to were conplane, or, more generally, took place about some fixed point. When the motion is conplane this point is at infinity, and the centroids are plane curves, sections of the cylindric ruled suraces formed by the successive positions of the instantaneous axes. When the distance of the point is finite, the centroids are, of course, spheric curves, the instantaneous axes forming cones of which the point mentioned is the vertex. These theorems were given by Poinsot in his "Théorie Nouvelle de la Rotation des Corps." It may be interesting just to mention also the case of general motion in space, where (as Belanger seems first to have pointed out), the solids of instantaneous axes, or axoids, as Reuleailx calls them--are general ruled surfaces twisting on each other. Each generator of the surface is a "screw," and on each in turn a twist occurs. The surfaces are in general non-developable.

For the sakei of brevity, only complane motions will be considered in this paper. This class of motions includes nine-tenths of those occurring in mechanism. Two or three special cases of frequent occurrence may first be mentioned. If the relative motion of two bodies be a simple rotation, the centroids are a pair of coincident points, one of which must still be considered to roll on the other. The instantaneous centre here becomes a permanent centre. It is convenient, however, to treat the point not only as a permanent centre, but as a special (limiting) case of the centroid. If all points in a body move in parallel straight lines, the centroid for the motion of the body is a point at infinity, and the centroid of the body is also a point at infinity coincident with the former. If the path of the body were infinitely long, the two points would roll round each other. If, on the other hand, a body move parallel to itself, every point in the centroid for its motion (and therefore all points in its own centroid) must be at infinity. The two centroids must again be coincident, so that the motion is represented by the line at infinity rolling on itself. ${ }^{2}$

Proceeding now to notice the bearing of the theory of centroids upon some of the theorems of elementary mechanics, these may be taken in order of simplicity, commencing with those which involve only the notion of change of position. If, then, the line joining any moving point with the point of contact of its centroids be called its instantaneous radius, we can state the general theorem thus: The direction of motion of every point in a body is normal to its instantaneous radius. While this obviously includes the simpler special cases already examined, its form allows of direct application to the most general cases, and especially to all cases in mechanism. Two corollaries out of many which are deducible from it may be mentioned as of some special interest : (i.) The inst. radii of a point moving in a straight line are parallel ; and (ii.) the inst. radii of a point moving in a circle must pass through one poirt. In either case the centroids may be quite general curves, as is easily seen. These corollaries have important practical applications in me-

I Some physical conception of this case can easily be obtained by rolling one hyperbola upon another. The change in the appearance of the rolling as the point of contact recedes along either branch is very striking. 